\title{
POLOS AGROFLORESTAIS DE RIO BRANCO: MODOS DE VIDA E SEGURANÇA ALIMENTAR
}

\author{
Francileide Lopes do Nascimento ${ }^{1}$ \\ Vera Lúcia Silveira Botta Ferrante ${ }^{2}$ \\ Luiz Manoel Moraes de Camargo Almeida ${ }^{3}$ \\ Gustavo Fonseca de Almeida ${ }^{4}$
}

\begin{abstract}
Resumo
A proposta do presente artigo é apresentar os modos de vida de um grupo de agricultores familiares e procurar destacar o papel das mulheres e jovens no processo de construção social. Este grupo é beneficiário de uma política pública denominada polos agroflorestais. Trata-se de um projeto de assentamento rural desenvolvido no âmbito da administração pública municipal e estadual. A pesquisa de campo foi empreendida em três polos agroflorestais de Rio Branco que possuem características distintas. O caderno de campo foi o instrumento de coleta de dados utilizado para o registro dos relatos dos agricultores. Este estudo mostra que o grupo apresenta uma identidade social comum, os indivíduos são de origem rural, tinham condições de vida precárias, mas, de modo geral, a posse de um lote de terra proporcionou melhoria na qualidade de vida.
\end{abstract}

Palavras-chave: Polos Agroflorestais. Modos de vida. Mulheres. Jovens.

\section{AGRO-FOREST POLES IN RIO BRANCO: WAYS OF LIVING AND FOOD SAFETY}

\begin{abstract}
The purpose of this article is to present the ways of life of a group of family farmers and to seek to highlight women's and young people's role in the process of social construction. This group is the beneficiary of a public policy called agroforestry poles. It is a rural settlement project developed within the scope of the municipal and state public administration. The field research was performed in three agroforestry poles in Rio Branco that have different characteristics. The field notebook was the data collection instrument used to record farmers' reports. This study shows that the group has a common social identity, the individuals are of rural origin and lived in precarious living conditions, but, in general, the possession of land plot provided an improvement in their quality of life.
\end{abstract}

Keywords: Agroforestry Poles. Ways of life. Women. Young people.

\footnotetext{
${ }^{1}$ Docente do Instituto Federal de Educação, Ciência e Tecnologia do Acre - IFAC. Mestre em Desenvolvimento Territorial e Meio Ambiente, Universidade de Araraquara - UNIARA. E-mail: Francileide.nascimento@ifac.edu.br. Doutora em Desenvolvimento Territorial e Meio Ambiente - UNIARA.

${ }^{2}$ Docente e Coordenadora do PPG em Desenvolvimento Territorial e Meio Ambiente (Mestrado e Doutorado), UNIARA. E-mail: dtmeioambiente@ uniara.com.br. Doutorado em Sociologia - UNESP.

${ }^{3}$ Docente e Pesquisador em políticas públicas da Universidade Federal de São Carlos - UFSCar, Campus Lagoa do Sino. E-mail: manoel77@ @ahoo.com.br. Doutorado em Sociologia - UNESP.

${ }^{4}$ Docente e Pesquisador em ciências agrárias da Universidade Federal de São Carlos - UFSCar, Campus Lagoa do Sino. E-mail: gufoal@ufscar.br. Doutorado em Agroecologia - Aarhus University, AU, Dinamarca.
} 


\section{Introdução}

A descoberta do processo de fabricação de borracha tendo como matéria-prima o látex extraído da Hevea brasiliensis, árvore nativa da região Amazônica, fez despertar o interesse pela ocupação do Estado do Acre, liderado por grupos econômicos estrangeiros e brasileiros. Conforme Pontes (2015), duas fases caracterizaram a ocupação: o primeiro ciclo da borracha (1870-1913), que teve fim com a concorrência dos seringais de cultivo, sobretudo na Malásia; e o segundo ciclo, que abrange o período de 1939 a 1945, para atender aos aliados durante a Segunda Guerra Mundial. Com o fim do conflito, a compra da produção de borracha do Acre foi interrompida e, com isso, os donos dos seringais declararam falência.

Estes acontecimentos resultaram em mudanças na estrutura produtiva do Estado. Os trabalhadores envolvidos nos sistemas de produção da borracha ficaram sem condições de permanecer na produção extrativista. Os antigos seringalistas teriam vendido suas terras para os "paulistas". Em outros casos, as terras foram alvo de grilagem. Por isso, uma parcela significativa dos seringueiros deixou de trabalhar na floresta.

Diante do êxodo rural e de seus problemas associados, algumas políticas públicas foram aprovadas como resposta aos problemas oriundos dessa nova realidade, que teve como consequência a urbanização acelerada e desorganizada. Conforme Toni (2006), em meados da década de 1990, a Prefeitura Municipal de Rio Branco criou um projeto de assentamento rural denominado polos agroflorestais, que se localizavam no entorno da cidade. $O$ projeto foi idealizado para receber a população que saiu de áreas rurais do Estado e se fixaram em áreas de risco na cidade.

Analisar os aspectos multidimensionais dos polos agroflorestais, pouco discutidos na literatura brasileira. registrar o modo de vida dos produtores rurais, apresentando as formas de organização social, relações familiares, com ênfase na função das mulheres nas famílias, formam o núcleo deste artigo.

Além dos aspectos de sociabilidade, também foram abordadas as formas de cultivo/comercialização e segurança alimentar dos agricultores.

\section{Metodologia}

Para a compreensão e análise dos dados pesquisados, este estudo foi desenvolvido por meio de uma abordagem metodológica qualitativa. Gerhardt e Silveira (2009, p. 31) explicam que a pesquisa qualitativa "não se preocupa com representatividade numérica, mas, sim, com o aprofundamento da compreensão de um grupo social, de uma organização etc."

O caderno de campo foi o principal instrumento de pesquisa, conforme Lopes (2002), o diário ou caderno de campo é um recurso muito utilizado pela etnografia para registrar as observações e reflexões durante os diálogos com os sujeitos da pesquisa, apontando informações sobre seu modo de vida e hábitos alimentares.

Outro instrumento de pesquisa utilizado foi o roteiro de entrevista. Os dados foram obtidos por meio de entrevistas com gestores públicos da Secretaria Municipal de Agricultura

\footnotetext{
5 "Paulistas" era uma expressão pejorativa utilizada para fazer referência aos empresários do centro-sul durante a década de 1970 e 1980. Todos aqueles procedentes do Mato Grosso até o Rio Grande do Sul eram considerados "paulistas" e representavam uma ameaça aos trabalhadores rurais nativos da região. (CARDIA, 2010).
} 
Familiar e Desenvolvimento Econômico - SAFRA e da Secretaria de Estado de Agropecuária - SEAP.

A pesquisa documental, por meio de dados obtidos junto à administração pública municipal e estadual, possibilitou o resgate histórico da construção da política pública em análise e complementou a análise qualitativa.

A pesquisa foi realizada no período de janeiro, fevereiro, julho e agosto de 2019 e janeiro de 2020. Participaram 89 produtores, chefes de famílias assentadas; dezessete famílias do polo Custódio Freire, trinta e quatro famílias do polo Wilson Pinheiro e trinta e oito famílias do polo Geraldo Fleming.

\section{Resultados e Discussões}

\section{Universo Empírico}

O objeto de pesquisa deste estudo correspondeu ao polo agroflorestal Wilson Pinheiro, administrado pelo governo do Estado do Acre, e os polos Geraldo Fleming e Custódio Freire, sendo ambos geridos pela Prefeitura Municipal de Rio Branco. Além de diferenças relacionadas à esfera de administração responsável pela gestão, é possível elencar outras características de distinção: tamanho dos lotes, localização, tipos de cultivo, infraestrutura e o tempo de criação. A figura 01 ilustra a localização dos polos no município de Rio Branco.

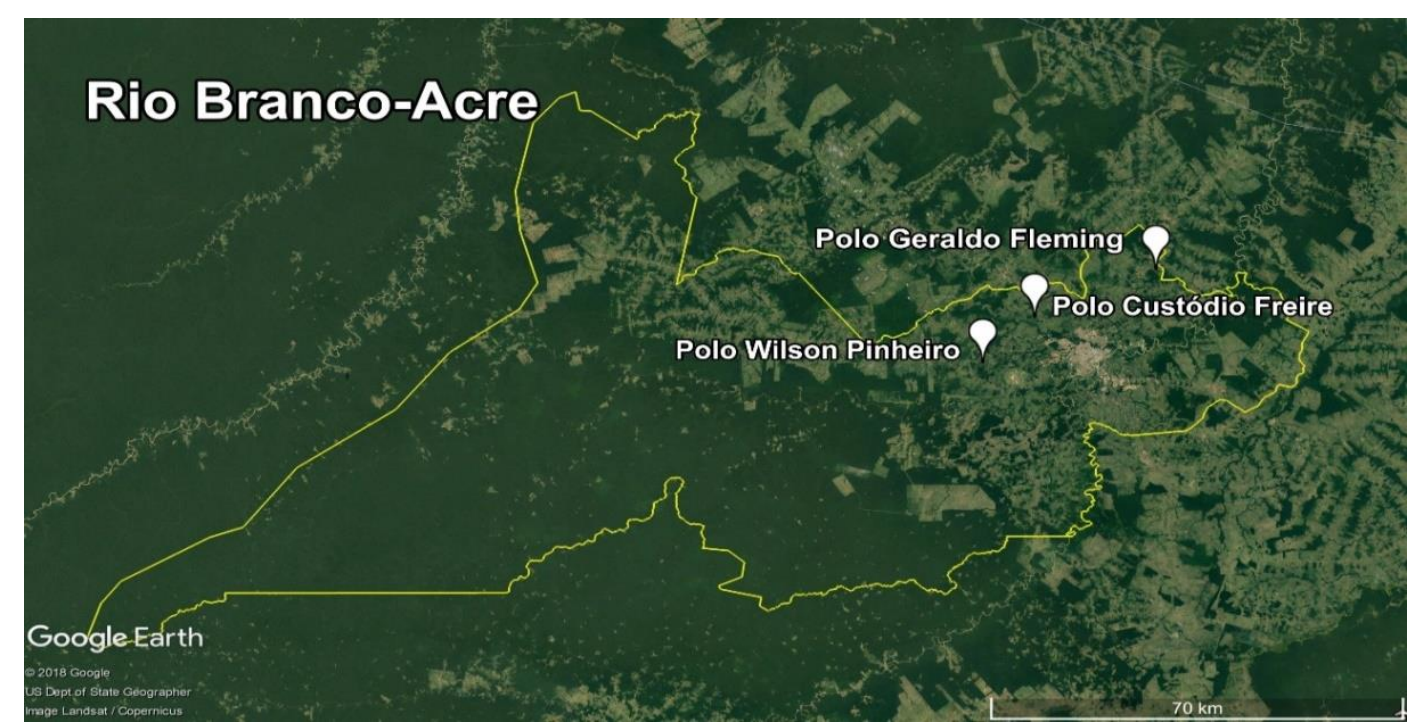

Fonte: Google Earth (acesso em 27 set. 2019).

Figura 01 - Localização dos Polos Custódio Freire, Geraldo Fleming e Wilson Pinheiro

A gestão dos polos administrados pela prefeitura de Rio Branco está fundamentada na Lei Municipal $n^{\circ} 1.484$, de 02 de dezembro de 2002, que define as obrigações dos assentados e estabelece outras questões, como a concessão de direito real de uso, válido por um período de dez anos. Após esse período, compete à prefeitura de Rio Branco expedir título definitivo não oneroso aos produtores rurais. A lei também apresenta uma relação de atividades econômicas que poderão ser desenvolvidas nos polos: hortifrutigranjeiro, culturas permanentes, culturas temporárias, pecuária, florestas e outras que vierem a ser incentivadas pelo município. O quadro 
1 apresenta uma síntese das principais características dos polos agroflorestais, estudados nesta pesquisa.

Quadro 1

Características dos polos agroflorestais Custódio Freire, Geraldo Fleming e Wilson Pinheiro

\begin{tabular}{l|c|c|c}
\hline \multirow{2}{*}{ Características } & \multicolumn{3}{|c}{ Polos Agroflorestais } \\
\cline { 2 - 4 } & Custódio Freire & Geraldo Fleming & Wilson Pinheiro \\
\hline Tamanhos dos lotes (ha) & 2,5 & 4,5 e 7,0 & 5,0 e 8,0 \\
\hline Famílias assentadas & 20 & 60 & 40 \\
\hline Ano de Ocupação & 1993 & 2000 & 2000 \\
\hline Esfera administrativa & Municipal & Municipal & Estadual \\
\hline Principais Cultivos & Hortaliças & $\begin{array}{c}\text { Hortaliças, criação de } \\
\text { animais. }\end{array}$ & Frutas, vegetais \\
\hline
\end{tabular}

Fonte: Elaboração própria.

\section{Processo de Ocupação: a decadência da economia da borracha}

A decadência da economia da borracha teve como consequência a redução da renda dos seringueiros, trabalhadores que realizavam a extração de látex. Alguns resistiram e permaneceram na floresta, desenvolvendo outras atividades extrativistas, como a coleta de castanha do Brasil e praticando caça e mantendo pequenos roçados para subsistência. No entanto, a maioria dos seringueiros optou por migrar para cidades em busca de uma nova ocupação de trabalho.

A falta de acesso a serviços públicos básicos como assistência à saúde tornava difícil a vida nos seringais, influenciando na decisão de mudança de vida. O que pode ser constatado no relato de uma produtora do Polo Geraldo Fleming.

Eu cheguei a passar muita dificuldade no seringal. Foi na época que meu pai ficou doente, foi pra cidade se tratar e eu e meus irmãos ficamos lá com meus tios. A gente chegou a não ter quase nada pra comer, era sofrimento mesmo. Eu sinto saudade de morar na mata, mas a vida lá é difícil. Quando eu vim com meu marido pra cidade como nós não tinha estudo a gente procurou trabalhar na produção, nas fazendas lá pra cima. Aqui no polo, graças a Deus, a gente não passou dificuldades. Só foi difícil no começo, pois a gente teve que esperar para colher. (Caderno de campo A 03/01/2020).

Cabe destacar que, segundo Castelo (2014), os seringueiros muitas vezes não tinham liberdade para preparar roçados, pois os donos dos seringais exigiam que se dedicassem somente à extração do látex. Essa também era uma forma de garantir a compra de alimentos vendidos nos barracões que eram de propriedade dos seringalistas, tornando os seringueiros continuamente endividados. Essa era uma característica do que se convencionou chamar de sistema de aviamento ${ }^{6}$. Por isso, muitos seringueiros, quando tiveram que deixar os seringais para trabalhar, tiveram dificuldades para se adaptar ao trabalho na agricultura.

A população oriunda dos seringais e outros trabalhadores rurais migraram para Rio Branco em busca de melhores condições de vida, mas, devido à falta de estudos e de recursos

\footnotetext{
${ }^{6} \mathrm{O}$ sistema de aviamento era um mecanismo utilizado pelos seringalistas para manter os seringueiros sob seu domínio por meio de dívidas. Sem outra alternativa de abastecimento, os trabalhadores endividaram-se comprando seus suprimentos de atravessadores contratados pelo patrão (CARDIA, 2010).
} 
financeiros, não encontraram ocupação e passaram a viver em áreas de risco, formando os bairros localizados às margens do Rio Acre. Esses trabalhadores não se adaptaram à vida no meio urbano, conforme relato de uma agricultora do polo Wilson Pinheiro:

Não sou daqui, sou de Feijó, a gente veio porque meu sogro tinha prometido tirar uma terra pra gente no final da Transacreana. Eu também morava lá em Feijó na zona rural; como meu sogro veio pra cá e meu marido só vivia atrás dele, nós viemos pra cá. Quando chegamos aqui, meu sogro não tinha tirado terra e nós fomos morar lá naquele bairro Preventório. Eu passei um ano dentro da cidade, mas chateada. Os meninos da prefeitura disseram que ia abrir os lotes e fazer sorteio; ainda bem que fui sorteada e fui pra lá. (Caderno de campo, 15/08/2019).

Entre os assentados também existem pessoas vindas de outras regiões do país, principalmente do Centro-Oeste e Sudeste, que já residiam no Estado antes da criação dos polos. Alguns deles moravam nos projetos de assentamentos que não foram bem sucedidos e outros trabalhavam em fazendas tanto na capital como em outros municípios.

Os moradores que residem desde o início da ocupação dos polos Geraldo Fleming e Wilson Pinheiro relataram que receberam os lotes, após serem sorteados pela prefeitura. A ocupação do polo Custódio Freire ocorreu de maneira distinta da dos demais, uma vez que não foi realizada seleção para escolha dos beneficiários. Foram assentadas pessoas que trabalhavam em fazendas nas adjacências da sede atual do polo, próximo ao perímetro urbano de Rio Branco, conforme o seguinte relato.

O Jorge Viana durante a campanha pra prefeitura veio nas fazendas e prometeu alugar uma terra adiante pra gente trabalhar. A gente trabalhava na terra dos outros. Quando ganhou ele alugou até 1997, até arrumar essa terra pra gente. Depois mudamos pra cá, todo mundo veio. Nasci em São Paulo, mas me criei em Mato Grosso do Sul. A gente veio porque o pai do meu marido veio aqui só comprar terra. Falou que aqui tinha como ganhar dinheiro, ele levou umas bananas compridas grandes e um arroz graúdo pra mostrar o que tinha aqui. Ele comprou mil hectares na estrada de Sena. Ele convenceu meu marido e a gente veio. Meu marido com meu irmão disse "vamos pra lá com a gente trabalhar, com dois anos a gente compra um sítio no Mato Grosso do Sul". Cheguei aqui em 1975, só que não deu certo, o que a gente conseguiu foi doenças, pegamos malária e nunca mais voltamos. Trabalhamos na fazenda do pai do meu marido e depois de oito anos conseguimos uma terra do INCRA lá em Sena. O meu irmão veio pra Rio Branco em 1986 e me trouxe pra cá. (Caderno de campo, 09/08/2019).

Esses relatos confirmam o que consta no discurso oficial: a proposta dos polos agroflorestais surgiu de uma iniciativa da gestão pública municipal de Rio Branco para resolver o problema do êxodo rural. De acordo com o gestor público responsável pelos polos geridos pela prefeitura, o prefeito da época (1993-1996) entendia que o Instituto Nacional de Colonização e Reforma Agrária - INCRA destinava cerca de cinquenta hectares para uma única família e a prefeitura poderia assentar uma maior quantidade de famílias em pequenas áreas degradadas.

Os polos agroflorestais foram criados com base em decisão política; apesar disso, sua criação envolveu conflitos sociais entre os grandes pecuaristas que, a partir da década de 1970, 
adquiriram ou tomaram posse de terras em todo o Estado do Acre. Sentindo-se coagidos, em razão do poder dos novos latifundiários, os pequenos produtores decidiram mudar para a cidade de Rio Branco.

\section{Criação legal dos Polos Agroflorestais: a constatação de algumas transgressões}

Apesar de existirem desde a década de 1990, os polos administrados pela prefeitura surgiram oficialmente com a Lei Municipal $n^{\circ} 1.484$, de 02 de dezembro de 2002. A lei trata dos objetivos da política municipal agrícola e fundiária e definiu a Secretária Municipal de Agricultura Familiar e Desenvolvimento Econômico - SAFRA como o órgão responsável pela formulação dessas políticas. O Artigo 10 da referida lei apresenta as obrigações dos assentados:

Art. 10. Os produtores assentados ficam obrigados, além das obrigações previstas no Estatuto da Terra, a empregar os melhores esforços na administração do imóvel e seguir as normas abaixo especificadas:

I - residir com a sua família no imóvel, explorando-a direta e pessoalmente, sendo vedada a exploração por terceiros, sob pena de revogação da concessão; II- atender às orientações do Conselho Municipal de Desenvolvimento, bem como permitir a fiscalização do Município, por meio da Secretaria Municipal de Agricultura e, quando necessário, da Secretaria Municipal de Meio Ambiente;

III- não desenvolver e explorar atividade comercial de qualquer natureza, sem expresso consentimento da Secretaria Municipal de Agricultura, após levantamento técnico da viabilidade ou necessidade de exploração, visando prejudicar, direta ou indiretamente, o harmônico desenvolvimento da vida rural, de acordo com o previsto nas disposições gerais e transitórias do Estatuto da Terra;

IV- não construir mais de uma moradia no mesmo imóvel;

$\mathrm{V}$ - preservar todos os bens naturais e sítios ecológicos que representem patrimônio ambiental. Não destruir ou danificar floresta considerada de preservação permanente, sem permissão da autoridade competente, mesmo que em formação, ou utilizá-la com infringência das normas ambientais, bem como, desmatar indiscriminadamente, sem imediato aproveitamento agrícola do solo;

VI - não vender, hipotecar, trocar ou alienar de qualquer modo o imóvel e outras benfeitorias realizadas;

VII- respeitar os limites e confrontações do imóvel rural;

VIII - não se tornar elemento de perturbação para o desenvolvimento do Polo Agroflorestal por má conduta e inadaptação à vida comunitária;

$\$ 1^{\circ}$. em caso de desistência da ocupação do imóvel o cessionário fica obrigado a informar por escrito a Secretaria Municipal de Agricultura, que imediatamente deverá tomar as providências cabíveis para o ingresso de outro produtor que atenda aos critérios estabelecidos;

$\$ 2^{\circ}$. no caso de morte do cessionário, a concessão poderá ser transferida ao herdeiro do cônjuge que comprovar o cumprimento das condições desta Lei.

Cabe ressaltar que, durante a pesquisa de campo, verificou-se que algumas dessas obrigações não foram cumpridas pelos assentados. Por exemplo, em todos os polos foi constatado o descumprimento da proibição de construir mais de um imóvel por lote. Essa situação é ainda mais recorrente no polo Custódio Freire onde, diferentemente dos demais polos, os agregados não desenvolvem agricultura. A maioria dos filhos dos assentados construiu sua casa no polo devido à proximidade com a área urbana, onde trabalham. 
A proibição de trocar o imóvel e suas benfeitorias é fundamental para coibir a especulação imobiliária que poderia descaracterizar a política. Mesmo assim, a venda dos lotes é algo comum e o mais grave é que acontece desde o início do programa, conforme relato de um assentado.

No meu caso, nós tamos aqui há 19 anos, o polo já existia tinha três meses. Trocamos por uma casa em Rio Branco. Eu tava inscrito na SAFRA, mas não fui selecionado porque era funcionário do Araújo. Antigamente teve a invasão dos sem terra, a terra era da Prefeitura, como teve a invasão, ela decidiu assentar logo o povo. Nenhum dos invasores ficou na terra, a prefeitura tirou e foram assentados no Wilson Pinheiro. Aqui ficou os selecionados da prefeitura. (Caderno de campo, 26/07/2019).

Outros produtores declararam que conseguiram o lote por meio de troca de casa na área urbana de Rio Branco. O comércio de lotes também é algo comum, entrevistamos uma família que veio de Rondônia e comprou o imóvel há cerca de três anos. Em uma das chácaras havia placa de vendas. As más condições dos ramais (base revestida com piçarras) contribuem para maior rotatividade de assentados no polo Geraldo Fleming.

Uma das moradoras mais antigas do Wilson Pinheiro informou que, após dez anos de ocupação, os ramais foram pavimentados com asfalto. No início da formação do polo os produtores passaram por muitas dificuldades, os lotes foram entregues sem nenhuma benfeitoria, cabendo aos produtores a abertura das áreas. Foram assentadas quarenta famílias, atualmente apenas cerca de vinte permanecem no polo. Ressalta-se que, ao longo do tempo, novos assentados assumiram os lotes dos antigos beneficiários.

O polo Custódio Freire apresenta realidade distinta, a comercialização ou troca de lotes é mínima, apenas um morador vivia há menos de um ano no local. Suas vantagens são a localização privilegiada e a renda média mensal auferida nesse polo, que é de $\mathrm{R} \$ 4.095,53$, enquanto nos demais a renda média mensal corresponde a menos da metade (Geraldo Fleming, R\$1.996,35 e Wilson Pinheiro, R\$1.920,28).

O gestor público responsável pela administração dos polos foi questionado sobre quais ações estão sendo realizadas para combater o problema do comércio/troca de lotes. De acordo com o gestor, a lei de criação dos polos agroflorestais proíbe a venda de lotes, mas é permitida a troca, desde que comunicada à SAFRA. O candidato a se tornar assentado geralmente é indicado pelo antigo morador e deve ter perfil para o trabalho agrícola e mão de obra familiar. Caso o novo morador não possua perfil de produtor familiar, a SAFRA notifica o atual ocupante e é aberto um processo de recuperação do lote com base na Lei Municipal no 1484.

\section{Formas de Cultivo e Comercialização: perspectivas de incentivo à produção orgânica}

Os polos agroflorestais de Rio Branco podem ser considerados sistemas mistos. Conforme o SENAR (2017), os sistemas mistos são uma das formas de classificação dos sistemas agroflorestais com base no arranjo dos componentes. Tem por característica uma mistura de componentes dispostos na área, entre eles os pomares caseiros, quintais agroflorestais e sistemas agroflorestais sucessionais. A sucessão de culturas permite a existência de plantas ao longo do ano. 
Durante a pesquisa de campo, constatou-se que a estrutura produtiva existente nos polos é bastante simples, principalmente em relação às estufas e ao sistema de irrigação. No período conhecido como inverno amazônico, que compreende janeiro a abril, os produtores precisam construir estufas para que as fortes chuvas não acarretem danos à produção. Os desgastes causados nas estruturas devido às intempéries exigem que este trabalho seja realizado todos os anos. A figura 2 apresenta uma área de cultivo protegido no Geraldo Fleming.

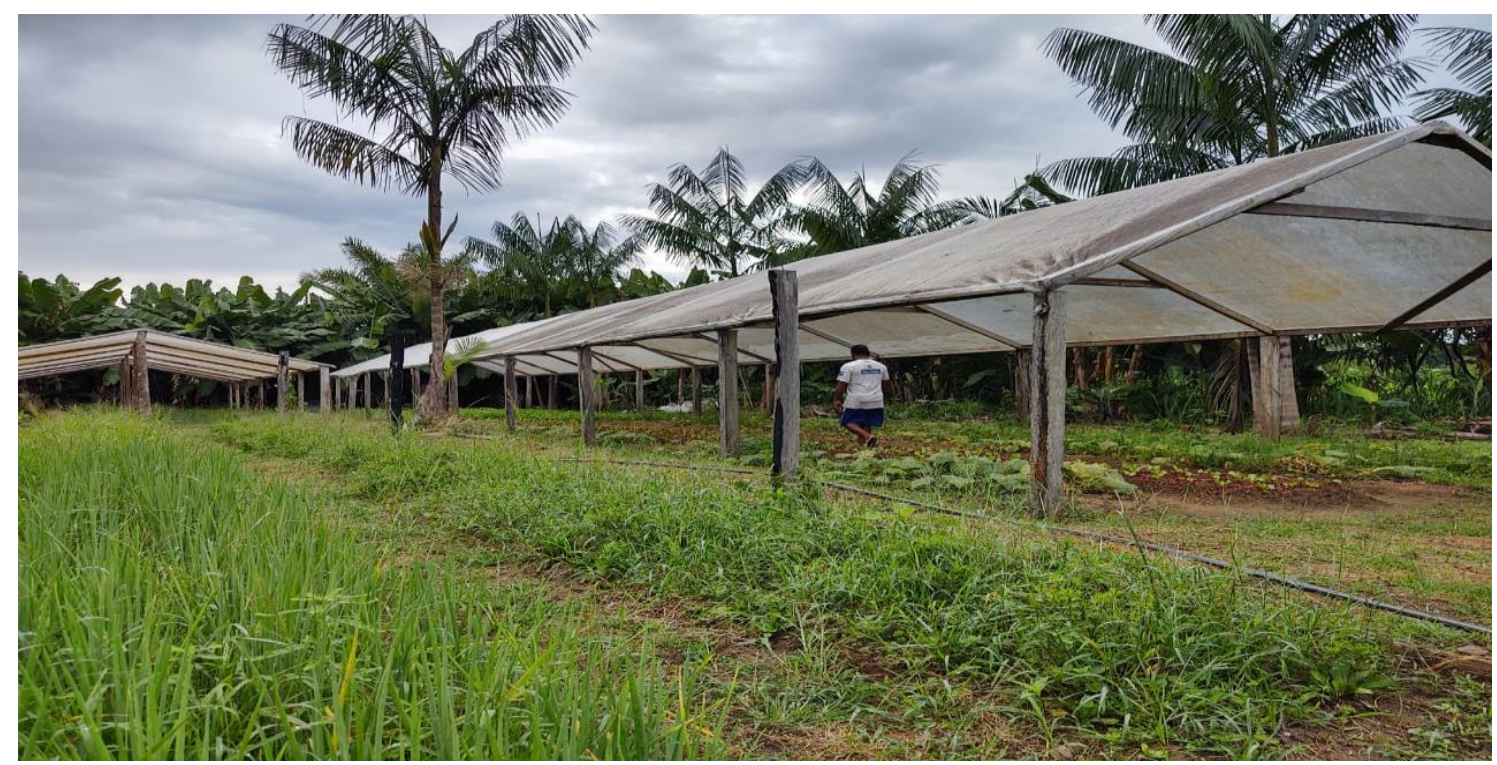

Fonte: Pesquisa de campo, 2020.

Figura 2 - Área de cultivo, polo Geraldo Fleming

Os produtores também buscam desenvolver cultivos consorciados, como previstos nos sistemas agroflorestais, auxiliando a recuperação do solo e a diversificação da produção. A produção consorciada está vinculada principalmente ao plantio de frutas e macaxeira.

A criação de animais é destinada para o mercado e autoconsumo. A estrutura para guarda dos animais é simples e pequena, utilizada apenas no período de chocar os ovos. Outras criações estão presentes em alguns lotes, como Peru, capote, suínos que são criados "soltos", no quintal. Geralmente, a venda dos animais ocorre quando há excedente.

Verificou-se que os produtores do polo Wilson Pinheiro têm interesse em iniciar a produção de peixes. Porém, para iniciar ou dar continuidade à criação, é necessária a recuperação dos açudes, mas a falta de recursos próprios impede a realização dos serviços. Os agricultores consideram essa atividade viável para a região, mas seriam necessários incentivos como linhas de financiamento específicas para piscicultura.

A proposta governamental para produção previa estimular o desenvolvimento da agricultura de forma equilibrada com o meio ambiente. Conforme Paula (2014), desde 2011 os produtores familiares do município que têm interesse em aprender técnicas de compostagem recebem treinamento na Unidade de Tratamento de Resíduos Sólidos de Rio Branco - UTRE. O resíduo orgânico oriundo das feiras e mercados municipais e materiais provenientes de podas realizadas pela prefeitura são levados para o centro de compostagem na UTRE e são transformados em adubos que podem ser utilizados nas suas hortas. 
Com área de $2.580 \mathrm{~m}^{2}$, a unidade de compostagem da UTRE tem capacidade de processar até 30 toneladas ao mês de material orgânico. Até agora já foram produzidas mais de 500 toneladas de adubo orgânico para os produtores de hortaliças dos polos agroflorestais, instituições sociais e hortas comunitárias, além do atendimento de demandas pontuais. (PAULA, 2014).

De acordo com a autora supracitada, o projeto de produção de compostagem orgânica da Unidade de Tratamento de Resíduos Sólidos teve seus resultados reconhecidos com a quinta edição do Prêmio Objetivos do Milênio - Brasil, em 2014, sendo a iniciativa foi uma das trinta experiências vencedoras.

Essa atividade de incentivo à produção orgânica atende também ao projeto hortas escolares, que é um projeto da Secretaria de Meio Ambiente em parceria com a SAFRA; os produtores recebem capacitação teórica e prática durante a montagem dos canteiros. Esse treinamento ocorre durante o ciclo de produção do adubo, que dura de três a quatro meses. $\mathrm{O}$ composto produzido é destinado para hortas escolares, jardins públicos e aos produtores selecionados dos polos Geraldo Fleming e Custódio Freire que participam do projeto (PAULA, 2014).

Outras instituições também desenvolvem ações de incentivo à produção orgânica nos polos. Um exemplo é o trabalho realizado pela superintendência do Ministério de Agricultura, que ofertou um curso de agricultura orgânica e conduziu a formação de um grupo composto por trinta produtores, incluindo todos os polos. O objetivo era a criação de uma feira, após o acompanhamento da transição da agricultura convencional para a orgânica, período de um ano e seis meses.

A comercialização desses produtos é realizada em feira localizada no centro da cidade, próximo ao mercado municipal Elias Mansour. Devido às dificuldades em ofertar uma produção agrícola totalmente orgânica, alguns produtores decidiram abandonar o projeto, conforme relato a seguir:

Tem uma certa dificuldade de trabalhar com orgânico, a gente não tem assistência técnica. A gente não tem insumo, as condições não é que não tem, falta recurso pra aplicar. Porque a gente precisava de mecanização boa, a gente precisava de ter máquina pra que a gente pudesse puxar, porque não eu aqui na mão que vou brocar aqui que vou colocar um saco, dois saco de produto orgânico pra compostagem fazer uma coisa... era muito difícil. Eu ainda produzo ainda, não uso agrotóxico, não uso produto químico é muito difícil. Mas chegando na feira no momento que tu chega na feira e tu vai fazendo cliente, o cliente vai exigindo de tu, o produto tal, o produto tal. Se tu tem banana e farinha, mas aí ele quer uma goma, uma tapioca, um cheiro verde, um alface e aí vai. Aí assim, aí tu não tem. Qual é a tua opção pra tu segurar teu cliente? Se tu não tem naquele momento, vai ter que achar da onde tu tirar pra oferecer pra ele, porque se tu não tem aqueles produtos que ele tá te procurando, então tu perde. Então vou lá pra banca do fulano que fulano tem de tudo. Aí o que aconteceu, muitos não tinha aí passaram a comprar de outros, aí eu dizendo: gente não pode, não pode comprar, mas aí eles não ouvia. Aí foi indo, aí com quatro anos eu resolvi sair da agricultura orgânica. Aí eles ficaram meio chateados porque eu tinha saído. Porque é assim, a agricultura orgânica, ou é ou não é, porque quando a gente vai lá, a gente faz um curso, a gente tem acompanhamento e a gente assina um termo. A gente tinha sempre reunião no Ministério de Agricultura e o que eles passavam, olha gente o 
grupo, o grupo tem vinte produtor, se eu errasse e eu fosse punida eu levava o grupo todim, entendeu? Aí eu disse, eu não vou ser responsável, punida por uma coisa que eu não fiz. (Caderno de campo, 15/08/2019).

Alguns produtores afirmaram que a primeira dificuldade relacionada ao cultivo de orgânicos está na origem dos materiais utilizados para formação do composto orgânico. A utilização de esterco bovino não dá garantia de que o composto será $100 \%$ orgânico; caso tenha sido utilizado algum tipo de veneno nas pastagens que alimentam o gado, o material passará por contaminação.

É misturado porque ninguém pode tirar veneno por causa das doenças. Dá menos doença no verão, mas agora apareceu uma praga que ninguém sabe o que é, acaba com a cebola da noite pro dia. Veio um rapaz ensinar a gente fazer compostagem. O problema é que a gente não tem estrume de gado se for pegar nas fazendas, o veneno que passa no capim faz com que o estrume fique com veneno e mata as verduras. A gente usa mais fertilizante de urina da vaca. (Caderno de campo, 09/08/2019).

Meio a meio não é tanto convencional nem orgânico, mas é mais convencional. O orgânico tem que ser orgânico, tem que vir lá do esterco do boi orgânico, se o fazendeiro tiver passado veneno já não vai ser orgânico. Se eu for pegar esterco na granja e tiver hormônio já não vai ser orgânico, então se falar que é $100 \%$ orgânico já tá mentindo. Tipo no nosso caso a gente pega esterco, mas ninguém sabe o processo que é feito lá. (Caderno de campo, $11 / 08 / 2019)$.

Além disso, os produtores acreditam que deveria haver maior incentivo à adesão a esse tipo de cultivo. $O$ fomento da produção deveria ser realizado a partir de um programa governamental voltado especificamente para essa atividade. Tal visão aparece no seguinte relato: "O orgânico tem que ter um projeto bem elaborado pelo governo para dar assistência técnica bem trabalhada desde o começo até o fim".

Apesar das dificuldades em desenvolver a agricultura orgânica, alguns produtores reconhecem a importância de reduzir o uso de agrotóxicos para a preservação da saúde da sua família:

Assim não é $100 \%$. Às vezes quando a planta tá meia fraca, eu ponho aquele tal de MPK, mas pra borrifar, assim eu não ponho nas minhas plantas agrotóxicos, eu compro aquele tal biofertilizante que chamam bico doce, é dez reais o litro, mas eu compro pra borrifar porque eu como dali e meus filhos comem dali, minha família toda come dali. Então é assim, eu ainda tenho aquela preocupação, eu ainda adubo na terra, o resto é o esterco com carvão, o mato que a gente capina eu coloco todinho nele, vou fofando, aí é assim. (Caderno de campo, 15/08/2019).

A proposta dos assentamentos rurais de Rio Branco era possibilitar a geração de renda agrícola e também contribuir para a autossuficiência alimentar das famílias. Mas, de acordo com os produtores, diversas dificuldades impedem a ampliação da produção para o autoconsumo, como a qualidade do solo, o tamanho dos lotes, a capacidade de investimento e a mão de obra disponível. 
Poderia, mas a terra não ajuda. No caso a gente compra feijão, compra arroz se a terra fosse maior a gente poderia produzir aqui. Tanto maior e se ela fosse boa também, porque a nossa terra ela não é boa pra esse tipo de plantação, até a macaxeira ela dá ruim...banana, não dá banana boa a não ser essa enxertada, ela não produz a banana maçã comum, nem a prata comum, a terra. Quando dá é uns pesinhos bem pequeninhos. é só a da Embrapa. (...) a gente consegue produzir hortaliça porque é no adubo. (Caderno de campo B, 03/01/2020).

Poderia se a gente tivesse terra mais grande e outra que se a terra fosse boa, cultivar, porque muitos a gente planta e não dá. Banana, eu luto muito com banana aqui, mas não dá, não dá. Dá os cachos bonitos, o primeiro, o segundo, o terceiro já morre não vai avante. (Caderno de campo B, 06/01/2020).

A pessoa tem que ter o material né, a gente não tem tipo assim, um motor de arado, a gente não tem um motosserra, falta muita coisa pra gente assim, não material pra fazer uma casa de farinha tá entendendo, então é difícil. O dinheiro da feirinha não é lá essas coisas. A gente paga o carro. A gente paga a banca tá entendendo? E o dinheiro que faz a gente compra as coisas pra dentro de casa. (Caderno de campo B, 02/01/2020).

Até poderia se tivesse mais pessoas aqui, pra trabalhar, pra ajudar porque só nós dois pra trabalhar. Porque, quando a gente começa a capinar, o roçado lá atrás e vem, quando a gente chega lá no fim aí tem que começar na frente de novo que o mato já tá dessa altura. (Caderno de campo D, 03/01/2020).

Em relação à escolha do canal de comercialização, a figura do atravessador ainda é presente nos polos, a exemplo de outras regiões da Amazônia. Apesar de reduzir os lucros, a presença de atravessadores é motivada pela pouca mão-de-obra disponível. Encontramos lotes em que apenas duas pessoas trabalham na lavoura, dificultando a saída para a feira.

Verificou-se que alguns produtores atuam como atravessadores comprando a produção dos vizinhos para revender. Em outros casos, os produtores entregam produtos para os vizinhos que estão com falta de algum produto e posteriormente retribuem da mesma forma ou pagam os valores correspondentes, como explicou uma produtora do polo Geraldo Fleming "vende ou troca agora meu marido vai trocar dois metros de cheiro verde com vizinho porque o dele tá pequeno quando o dele tiver bom, ele me devolve". (Caderno de campo A, 03/01/2020).

Durante a entrevista, o gestor público responsável pelos polos afirmou que uma das prioridades da SAFRA é a organização de feiras. A feira é uma forma de comercialização importante, no sentido de retirar a figura do atravessador entre produtores familiares e consumidores finais, tendo em vista que esse intermediário adquire barato do produtor e vende caro ao consumidor final. A manutenção das feiras de bairros e mercados públicos é uma prioridade da SAFRA, que atualmente organiza trinta e quatro feiras. As bancas são de domínio da SAFRA e os feirantes recebem orientações de manuseio e de comercialização dos produtos, além de orientações sobre o comportamento nos espaços públicos.

Essa ação é de fundamental importância, uma vez que a SAFRA realiza o transporte da maior parte da produção comercializada nas feiras de bairros e nos mercados municipais e na CEASA, mantendo o abastecimento com produtos hortifrutigranjeiros locais, com custos reduzidos tanto para produtores rurais quanto para consumidores.

A SAFRA realiza, semanalmente, o transporte de aproximadamente 257 feirantes, participantes de feiras de bairros e também de produtores, que solicitam agendamento para levar 
sua produção aos mercados municipais e CEASA. A Secretaria dá o suporte para a realização do transporte da produção, oferecendo os caminhões, com motorista e grande parte do combustível necessário; apenas uma pequena parte deste é custeada pelos próprios produtores (SAFRA, 2017).

Parcela significativa dos produtores prefere comercializar dentro do mercado tradicional, principalmente a venda em feiras de bairro ou mercados públicos. Eles acreditam que a feira é a melhor alternativa, uma vez que elimina os intermediários que ficam com parte dos lucros e o capital de giro mais rápido, garante maior tranquilidade:

Feira é a opção que tem. Pra atravessador não compensa, para atravessador você tem que plantar em grande escala, aí tem que ter gente, ter mão de obra, aí não compensa, não. Governo é projeto, é uma vez por ano quando tem recurso. Se for plantar pra entregar pro governo tem que ter uma segurança. Quem se iludir em plantar pra vender pro governo tudo. O governo não compra tudo é só uma complementação de renda, não é pra absorver tudo. (Caderno de campo, 11/08/2019).

Eu só vendo na feira. Porque assim aqui tem umas entregas pro PAA, aqui tinha fome zero, aí a gente entrega e passa um mês, dois mês pra receber. Agora tá até melhor o preço, mais ou menos, mas era muito barato e era descontado muita coisa e passava um tempão pra receber, eu entregava e às vezes eu ia receber a primeira entrega bem no final da última, aí, rapaz, não dá, eu não gosto desse tipo de coisa. Meu negócio é minha feirinha, mesmo que venda mais barato tô com meu dinheiro na hora, na mão, faço o que eu quero. As feiras, eles oferecem as bancas, o caminhão, mas é nós que tem que manter, nós é que paga o montador, nós é que paga o óleo do caminhão pra vir buscar nós. (Caderno de campo, 26/07/2019).

O Programa de Aquisição de Alimentos, gerenciado pelo governo do Estado do Acre, trabalha atualmente com as modalidades de compra com doação simultânea e compras governamentais. Em relação à modalidade compra com doação simultânea ${ }^{7}$, o segundo gestor local entrevistado apontou que o principal problema do programa é a limitação dos recursos financeiros. Cada produtor recebe até $\mathrm{R} \$ 2.500,00$. Os recursos demoram a serem liberados, com isso não é possível estabelecer um cronograma para ser seguido todos os anos. Apesar dos entraves, o gestor ressalta a importância social do programa que incentiva a produção agrícola ao complementar a renda do produtor. O programa também fortalece as ações de instituições beneficiárias que realizam atividades de assistência social.

No que tange aos programas de compras governamentais PAA e PNAE, a renda destinada ao produtor varia conforme a modalidade aderida. De acordo com o gestor da modalidade de compras institucionais do PNAE, cada produtor pode receber até R $\$ 20.000,00$ anualmente. Nessa modalidade, são selecionadas cooperativas e associações que possuam a documentação exigida no edital e certidões negativas em todas as esferas de governo. Para o

\footnotetext{
${ }^{7}$ Destina-se a promover a articulação entre a produção de agricultores familiares e as demandas locais de suplementação alimentar e nutricional de escolas, creches, abrigos, albergues, asilos, hospitais públicos e outros, e dos programas sociais da localidade, tais como bancos de alimentos, restaurantes populares e cozinhas comunitárias, resultando no desenvolvimento da economia local, no fortalecimento da agricultura familiar e na geração de trabalho e renda no campo. (GRISA et alii, 2009).
} 
produtor participar desses grupos, é necessário ter Declaração de Aptidão ao PRONAF atualizada.

O gestor relatou que um dos entraves relacionados ao programa é a limitação de recursos humanos: apenas dois servidores da Secretária de Estado de Agropecuária trabalham para atender todo o estado. Por parte dos produtores, falta despertarem para o empreendedorismo, pois eles não demonstram interesse pelo cooperativismo e outras formas de organização. As poucas cooperativas e associações existentes possuem dificuldades de logística o que prejudica a participação no programa.

\section{O papel das mulheres assentadas: produção, alimentação e família}

Historicamente as relações de gênero no meio rural são caracterizadas por submissão das mulheres, daí a importância de investigar como estão estabelecidas essas relações na realidade local. Durante as visitas foi possível verificar situações em que o homem solicitava que a pesquisa fosse feita com a sua esposa e, em outras circunstâncias, a esposa respondia e o marido completava as respostas. As produtoras colocavam-se em igualdade com seus cônjuges ao se identificarem ambos como chefes da família.

A organização familiar passou por mudanças, principalmente nas famílias oriundas de seringais. Algumas mulheres tinham como função apenas o trabalho doméstico e os cuidados com os filhos; após a fixação nos polos, começaram a trabalhar no processo produtivo e na comercialização. Se a nova função trouxe uma sensação de autonomia, por outro lado, acarretou sobrecarga de atividades e o desafio de superá-la.

É comum encontrar propriedades onde as mulheres participam de todas as etapas do processo produtivo até a comercialização nas feiras, além de vender na feira e cuidar dos afazeres domésticos.

Aqui trabalho em tudo, trabalho no roçado, eu planto, eu colho, aqui trabalha três eu meu marido e meu filho. Quando tá no verão, quando não chove, é quase nós trabalha todo dia porque tem que alimpar. Cuido da minha casa cuido das minhas criações, mas ele ajuda também, quando eu tô muito aperreada, ele ajuda também. (Caderno de campo A, 02/01/2020).

Trabalho, mas não todos os dias, porque tenho que cuidar da casa. Tem que virar leira e eu planto, tenho que aguar. Trabalho três vezes na semana na plantação. Pra vender uma semana eu vou pra feira, na outra semana, ele vai. (Caderno de campo A, 03/01/2020).

Quando a gente acorda $05 \mathrm{~h} 00 \mathrm{~min}$ nem arruma nem as camas só levanta, faz um cafezinho e vai pra roça, aí quando chego 8:30 9:00 e pouco aí vou arrumar a cama arrumar casa vou botar feijão no fogo, quando não tem cozido, aí vou fazer a carne, arroz, vou fazer o almoço todo, aí ele vem também. À tarde a gente volta uma hora, uma e meia no máximo a gente volta pra roça e volta 16:00 e eu esquento a janta. (Caderno de campo D, 03/01/2020).

Eu faço tudo, só não faço aradar e fazer leira, mas eu planto, eu limpo, eu capino, eu faço colheita, não só eu, né, eu e ela, essa aqui é minha filha. Somos três, meu esposo no trabalho bruto mais pesado e a gente fica com o mais leve que a questão de limpar, adubar, aguar, fazer a colheita, a venda, tudo fica com a gente, todo dia a gente vai trabalhar. (Caderno de campo C, 03/01/2020). 
Algumas propriedades são conduzidas apenas por mulheres e, mesmo naquelas em que a produtora tinha cônjuge, ela era a responsável principal por tocar a lavoura.

Eu tenho 65 anos. Aqui trabalha eu, mais duas filhas e a neta ajuda sexta pela manhã, o dia de colher as verduras. Cria galinhas e peixe para o consumo da família e macaxeira planta pra comer. (Caderno de campo, 09/08/2019).

Um caso que merece destaque é o trabalho de uma produtora do polo Geraldo Fleming que, ao lado da sua irmã, se dedicava exclusivamente à criação de suínos. Este caso chamou atenção, uma vez que a criação de animais é um trabalho árduo e exige atuação diária por parte do produtor.

Apesar de a maioria das mulheres participarem de todo o processo produtivo, há aquelas que trabalham somente em alguma etapa da produção, como o plantio e a colheita. O relato a seguir mostra que a saúde debilitada pode reduzir a participação das mulheres nas atividades produtivas.

Eu não ajudo mais, porque tenho problema de coluna, eu não aguento tipo capinar, pra cuidar, limpar, é ele, eu não. Eu mais ajudo a plantar e a colher eu tenho dois disco e papagaio e hérnia na coluna agora pra tá agachada eu já não aguento. Os animais é eu, ele, às vezes, ele dá comida, é galinha, pato, a gente tá pensando em criar porco, às vezes, ele dá comida. (Caderno de campo $\mathrm{B}, 02 / 01 / 2020)$.

Em todas as famílias as mulheres eram responsáveis por fazer a comida, bem como escolher o cardápio das refeições. Foi possível identificar relatos nos quais as produtoras buscam manter os hábitos alimentares antigos, como forma de preservar memórias do seu local de origem.

Nossa prática não mudou, porque sou filha de seringueiro, fui criada no seringal, eu vim pra cidade eu já era adolescente, mas a minha prática não mudou eu como batata, jerimum, banana comprida, o pão de milho, a tapioca, esse é o nosso café da manhã, entendeu? Assim, pão, massa, a gente come, mas é muito pouco. (Caderno de campo A, 06/01/2020).

A gente compra uva, maracujá, compra... é variado, maçã, a gente compra o que tem na promoção, só não vai muitas vezes na promoção o que a gente gosta muito e a gente tem de desejo de comer e compra, caqui, que era uma fruta que eu era acostumada a comer no sul e continuei comendo. (Caderno de campo C, 03/01/2020).

As caças que tem aqui é tatu, paca, jabuti, uma vez por mês, mais no verão, a gente gosta porque a gente foi criado no seringal com carne de caça e peixe nativo. (Caderno de campo A, 03/01/2020).

Por outro lado, foi possível observar a inserção de alimentos industrializados, como refrigerantes, biscoitos, macarrão instantâneo, principalmente no cardápio de famílias com crianças. Além disso, mesmo com criação de galinhas em quase todos os lotes, os produtores compram frango no mercado, pois a quantidade de animais, em torno de trinta galinhas por lote, não é suficiente para a venda e o autoconsumo. É necessário manter as galinhas para abastecer 
a casa com os ovos. As agricultoras também relataram que vendem a galinha caipira por $\mathrm{R} \$$ 35,00 , sendo mais vantajoso vender as galinhas e comprar o frango no mercado. Essa prática mostra que a autenticidade da alimentação é deixada de lado em busca de maior renda agrícola.

O cardápio do café da manhã varia entre as famílias, excepcionalmente os moradores consomem pão, os alimentos mais consumidos são: farofa com ovo, macaxeira cozida, bolacha, banana comprida frita, o pão de milho (cuscuz) e a tapioca. Existem produtores que apenas tomam café, pois precisam acordar muito cedo para trabalhar na horta, para aproveitar a temperatura mais amena. No almoço e no jantar a base da alimentação é arroz, feijão e algum tipo de carne.

As agricultoras têm o costume de cultivar algumas ervas medicinais para tratamento de doenças da família. As principais plantas cultivadas são: Alfavaca, corama, malvariço, hortelã, cravo de defunto, anador, arruda, mastruz, dipirona, maracujina, erva cidreira e crajiru.

As famílias consideram os produtos oriundos da propriedade como a base de uma alimentação saudável, apesar disso não demonstram nenhum tipo de receio em relação à qualidade dos produtos oriundos do mercado. Fatores que impedem a ampliação da produção para o autoconsumo: o tamanho das áreas e problemas de fertilidade do solo. Até mesmo produtos básicos, como arroz e feijão, são adquiridos no mercado.

Outro fator é a proximidade do mercado; os polos formam um cinturão verde associado ao fato de que a maior parte deles se desloca toda semana para o centro urbano para comercializar nas feiras e mercados públicos, o que facilita as compras de gêneros alimentícios no mercado.

Quando questionadas se consideram a alimentação da família saudável, as agricultoras associam alimentação saudável com a existência ou não de doenças, percebe-se nos seguintes relatos "Acho que é, até agora, graças a Deus, ninguém adoeceu" (Caderno de campo A, 02/01/2020).

A alimentação, a gente não come verduras, come muita carne vermelha, fritura já atinge os pequenos, essa minha filha de nove anos teve tontura, levei ao medico, ele disse que tem colesterol alto. (Caderno de campo B, 03/01/2020).

Porém, foi possível verificar que muitas famílias não têm uma alimentação rica em frutas, legumes e verduras. A maioria das agricultoras informou que não come verdura todos os dias, pois é caro, mostraram que o fator renda influencia uma melhor alimentação. Em outros casos, elas não têm o hábito de consumir esse tipo de alimento. Entre as hortaliças oriundas da horta mais consumidas pelas famílias, destacam-se a cebolinha, chicória e couve.

A macaxeira é bastante consumida, sendo cultivada em quase todas as propriedades. Os principais vegetais comprados no mercado são a cebola e a batata. O consumo de frutas se dá de acordo com a disponibilidade na propriedade, ou seja, consomem as frutas da "estação".

O polo Geraldo Fleming apresentou maior quantidade de famílias que praticam a caça. Os homens e os filhos mais velhos praticam essa atividade. Os principais animais capturados são paca, cutia, macaco, tatu, considerados caça pequena. No polo Wilson Pinheiro, a caça deixou de ser praticada, pois não se encontram animais na floresta. O polo Custódio de Freire apresenta área de mata bastante reduzida o que impede a caça.

As mulheres destacam-se na organização social. Atualmente as associações de produtores dos polos Wilson Pinheiro e Custódio Freire são lideradas por agricultoras. No polo 
Geraldo Fleming, a gestão da associação de produtores, que concluiu suas atividades em 2018, era conduzida por uma mulher. Além disso, a liderança feminina está presente na organização de uma cooperativa que comercializa polpa de frutas.

No que tange ao papel das mulheres na família, elas são responsáveis pelos afazeres domésticos e também pela educação dos filhos. Quando questionadas sobre a participação dos cônjuges nesse processo, percebe-se que é uma responsabilidade exclusiva delas. "Eu que cuido da educação, ele não se intromete muito, não. É mais a mãe nessas horas assim" (Caderno de campo B, 02/01/2020). "Ele é lerdo demais, vixe. Eu que cuidava dos meninos" (Caderno de campo A, 03/01/2020). "Mas é eu e ela a responsabilidade da criança, reunião de escola, tudo" (Caderno de campo C, 03/01/2020). Pode-se afirmar que mulheres assentadas são sobrecarregadas, além de participarem ativamente das atividades produtivas, elas são responsáveis por cuidar da casa e dos filhos.

\section{Formas de sociabilidade e modo de vida nos polos}

Assim como os demais, o polo Geraldo Fleming conta com Associação de Produtores Rurais. Na visão dos assentados, a associação de produtores realiza ações que trazem benefícios para o polo, como buscar levar as reivindicações junto à Prefeitura, principalmente como entrega de materiais de apoio à produção. Além disso, a associação promove com frequência eventos para confraternização dos moradores, como pode ser observado na figura 03 .

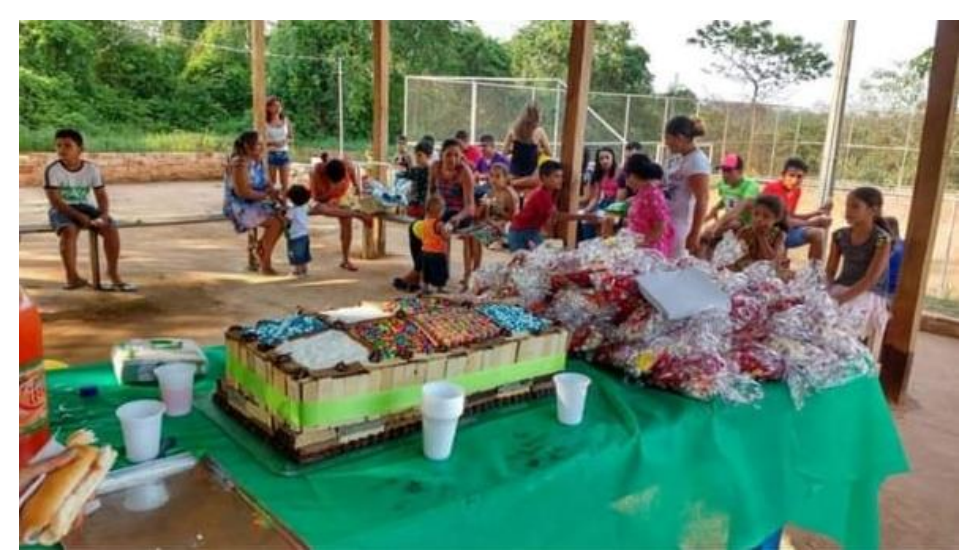

Fonte: Associação dos produtores rurais do polo Geraldo Fleming.

Figura 3 - Comemoração do dia da criança, polo Geraldo Fleming

A maior parte dos moradores é evangélica, mas devido à proximidade com a cidade muitos deles frequentam igrejas fora do polo. Apesar disso, os produtores consideram a igreja local como uma organização atuante, por meio de seu trabalho social que consiste na realização de visitas às famílias e distribuição de cestas básicas quando há necessitados. A figura 4 apresenta a imagem de uma igreja localizada no polo Custódio Freire. 


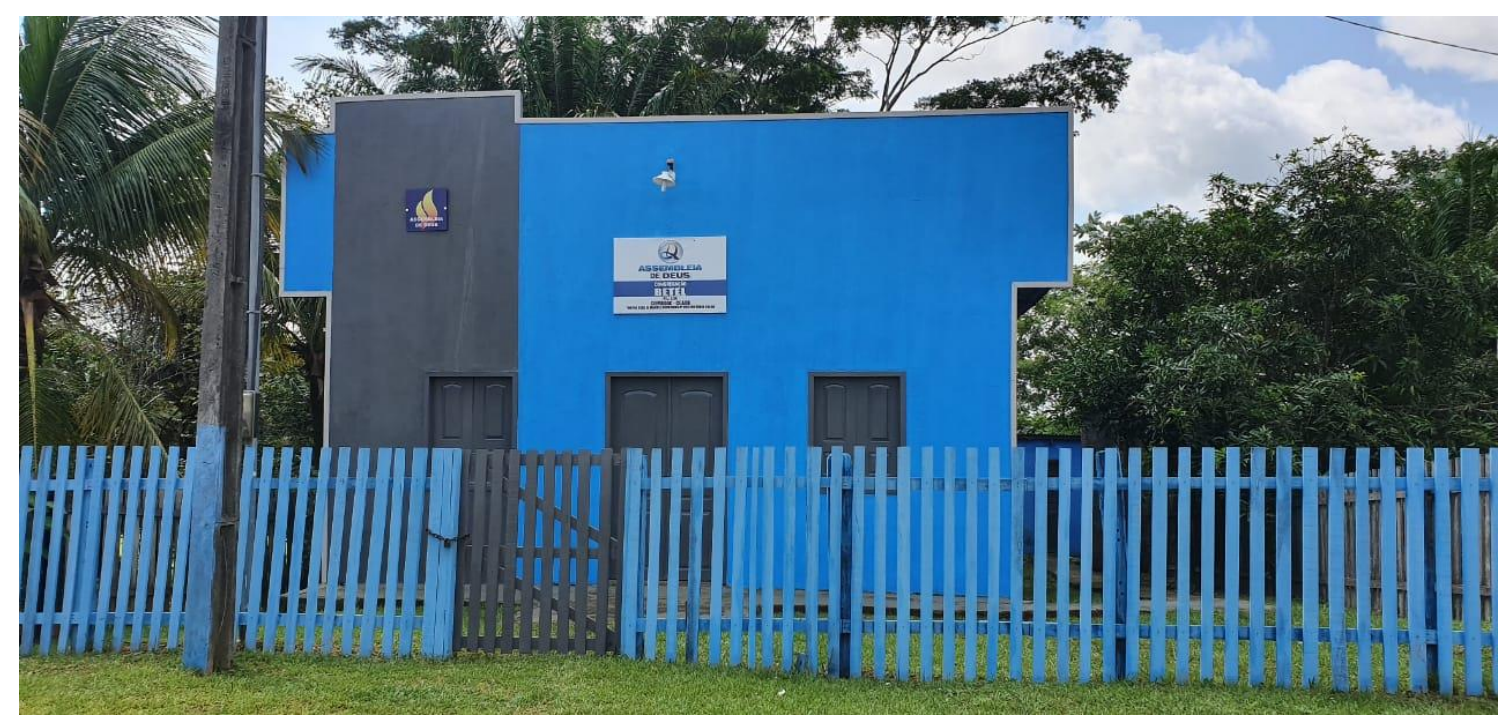

Fonte: Pesquisa de campo, 2020.

Figura 4 - Igreja Assembleia de Deus, polo Custódio Freire

A proposta dos polos agroflorestais era dar acesso à terra a pessoas oriundas de áreas rurais que, por diversos motivos, foram deixando a terra. Para compreender os resultados desta política na vida dos assentados é importante compreender as dificuldades enfrentadas pelos agricultores antes de se tornarem assentados.

Lá é bem diferente daqui lá eu era sustentada pelo marido tudo dependia dele tudo, tudo depois que cheguei aqui foi que mudou né, aí eu comecei a trabalhar, a sair pra conhecer a cidade. Tudo é nosso aumentou a renda ficou melhor não falta nada graças a Deus, aqui nunca passei fome depois cheguei aqui. Lá é muito difícil o custo de vida lá pra quem não tem estudo é muito difícil, pra quem mora na zona rural como a gente lá é não é uma vida boa não é muito difícil, lá a terra é pior do que aqui. (Caderno de campo B 03/01/2020). Quando era bem nova no seringal aí eu trabalhava eu quebrava castanha, eu cortava seringa, eu roçava de foice fazia todo serviço. Aí tinha um monte de menino. Pra criar esses menino tudo era um sacrifício oh. Eu tive 12 filhos tenho 10 vivo graças a Deus tive muita dificuldade lá. (Caderno de campo D 03/01/2020).

Durante os diálogos com produtores foi constatado que, de forma geral, na visão dos entrevistados as condições de vida e capacidade de prover alimentos eram piores antes dos assentamentos. Por outro lado, até a consolidação dos polos, os produtores passaram dificuldades em relação ao provimento de alimentação à família.

Quando veio morar aqui nem eu tinha emprego nem ele tinha emprego até as coisas crescer pra gente colher foi muito difícil mesmo, passei muito apuro tinha dia que não tinha nada pra comer nada mesmo tá. De um ano pra frente que as coisas melhoraram. (Caderno de campo A 03/01/2020).

De acordo com uma produtora do polo Custódio Freire no começo da ocupação, diante da falta de mão-de-obra e da necessidade de iniciar a produção, os moradores realizavam "mutirão", organizando frentes de trabalhos na maioria dos lotes. Superadas as dificuldades iniciais, esse tipo de trabalho coletivo deixou de ser realizado. Situação semelhante aconteceu nos demais polos, conforme relato de um morador do polo Geraldo Fleming. 
Antigamente ainda trabalhava assim uns tempo, ali pro outro ramal e aí era legal, fazia aquele grupo de gente trabalha um dia na colônia outro dia na outra de repente fazia o serviço certo, mas aí não funcionou não de repente pararam. (Caderno de campo A, 03/01/2020).

Buscou-se durante as entrevistas identificar qual a percepção dos assentados sobre a qualidade de vida nos polos e se eles consideravam que trabalhar/morar no lote é mais vantajoso que residir na cidade. De forma geral, os produtores estão satisfeitos e consideram que morar nos polos é a melhor opção que eles têm. Entre um dos motivos para essa visão está a possibilidade de realizar o autoconsumo a partir da sua produção.

Eu me sentia mal dentro da cidade quando chegava em casa meu filho me falava: aí mãe queria uma banana. Eu dizia se tivesse dinheiro comprava pro meu filho. Já eu tô aqui e meu filho ah quero uma graviola, graças a Deus tem. Eu tenho limão, tenho a laranja, tenho cupuaçu na produção. Eu fico feliz com isso, meu filho quer comer tem plantado tem fruta, deu tem. Aí assim, de tudo eu tenho pra eu comer e levo pra minha feira. Porque é assim, o que eu tenho eu não compro, mas o que eu não tenho eu preciso comprar. Se eu tivesse na rua eu ia depender daquele empreguinho. (Caderno de campo, 15/08/2019)

Além da possibilidade de reduzir a dependência de alimentos comprados nos mercados, também foi registrado o relato de uma produtora que exalta a importância do autoconsumo associado à alimentação saudável. O trabalho no polo e o cultivo orgânico, realizado no seu lote, proporcionam a garantia de estar consumindo alimentos saudáveis, diferente da maioria dos alimentos encontrados no mercado.

Primeiro porque eu gosto daqui. Segundo porque aqui eu posso ter uma alimentação natural, aqui tanto posso ter alimentação natural, como posso vender um produto natural. $\mathrm{E}$ aqui também eu compro só o básico o maior consumo meu sai daqui mesmo, tipo verdura, carne eu não como carne, mas peixe tudo tiro daqui. Eu prefiro morar aqui porque aqui eu moro e vendo meus produtos, não preciso trabalhar empregada lá na rua ganhar salário mínimo. Aqui eu faço meu salário e conforme meu trabalho eu aumento meu salário. (Caderno de campo, 12/08/2019).

Nos relatos dos assentados é possível verificar que a renda auferida e a possibilidade de ter independência, no sentido de trabalharem por conta própria, são fatores importantes para a permanência nos polos. Os moradores também preferem viver longe da agitação da cidade. A vida nos polos proporciona uma sensação de segurança, o que é apontado como uma vantagem pelos produtores, principalmente diante do crescimento dos índices de violência registrados em Rio Branco, nos últimos anos.

Eu continuo porque gosto de trabalhar com a terra. Sou aposentada a renda da aposentadoria não é suficiente pra viver, ainda bem que não sou doente porque se tivesse que comprar remédio seria pior. Aqui é bom pra viver não tem barulho de carro nem perturbação. (Caderno de campo, 09/08/2019).

Primeiro é bom de morar aqui, apesar do ramal tá melhor que a cidade, tranquilo, por enquanto, ninguém sabe até quando. Hoje na idade que nós tamos tá difícil arrumar emprego e ir pra rua pra ganhar um salário mínimo pra sair daqui vai tudo em passagem e alimentação que você vai ter que comer 
por lá alguma coisa assim, então não compensa então aqui tá bem melhor que arrumar emprego lá. Graças a Deus o que a gente paga a gente vive bem. (Caderno de campo, 11/08/2019).

Um dos entraves verificados nos polos é o fato de que as associações não atuam no processo de organização produtiva. Elas participam como interlocutores entre os produtores e a Prefeitura e governo do Estado.

\section{Dilemas da sucessão: a permanência dos jovens}

Atualmente, as famílias rurais encontram dificuldades em relação à sucessão do trabalho na propriedade, tendo em vista que a permanência dos jovens no meio rural não é algo certo, como era em um passado recente, no qual a imposição dos pais ou a questão cultural contribuíam para a redução do êxodo rural.

Segundo Carneiro (1998), a nova realidade está relacionada às mudanças ocorridas no meio rural, que passou a ser um espaço cada vez mais heterogêneo e às fronteiras com o meio urbano estarem se tornando cada vez mais próximas. Os jovens são os mais afetados nesse novo contexto, pois se sentem atraídos pelo mundo moderno e acreditam que o trabalho na agricultura não apresenta boas perspectivas para o futuro.

Essa nova condição também é verificada nos polos agroflorestais onde parcela significativa dos jovens demonstra o desejo de dar continuidade aos estudos. Para isso é necessário o deslocamento até a cidade. Além disso, almejam uma colocação no mercado de trabalho urbano.

O produtor rural desenvolve uma atividade penosa, essa característica torna o trabalho no campo pouco atraente para os jovens, conforme o relato de um produtor do polo Wilson Pinheiro.

A nossa lei foi formada aí dizendo que não pode botar mais jovem pra trabalhar, que de menor não pode trabalhar e quando chega de maior ele não quer mais nada na roça quer trabalho mais maneiro. Às vezes estuda e aqui não oferece estudo adequado tem que sair pra cidade pra estudar. Muitos já saíram, mas tem muitos que continua. (Caderno de campo, 15/08/2019).

Outro motivo de insatisfação dos jovens em relação à vida nos polos é a falta de acesso à internet e oportunidade para realização de cursos, conforme o relato de uma produtora do polo Wilson Pinheiro.

Os jovens eu vejo reclamar, porque os amigos da minha filha andam aqui e eles acham ruim aqui porque não tem internet, quando precisa fazer um trabalho tem que ir lá na cidade. Eu acredito que muitos querem ir embora porque não tem oportunidade, eles não têm como fazer um curso. A minha filha reclama porque se tivesse na cidade tinha entrado pro bombeiro mirim, feito o curso de inglês de graça que tavam dando de graça e aqui não tem essas oportunidades. (Caderno de campo, 31/07/2019).

Em relação à opinião dos familiares sobre a possibilidade de os filhos deixarem a propriedade, as posições se dividem. Existem famílias que desejariam que os jovens permanecessem no polo e outras que apoiam totalmente a decisão de buscarem outro tipo de atividade na cidade, pois consideram a vida no campo bastante difícil. 
A maioria dos jovens quer ir embora dois netos falaram que querem ir embora pra "rua" (cidade) pra estudar e trabalhar. Eu tenho uma neta que se forma esse ano em psicologia. Eu como avó fico triste por sair daqui, mas a decisão é deles, tem que respeitar. (Caderno de campo, 09/08/2019).

A maior parte não fica aqui não, mora aqui, mas arruma trabalho na cidade. $\mathrm{O}$ daqui de casa trabalha de manhã a tarde ajuda nós e faz faculdade a noite. Eu quero que procure outro ramo a gente luta porque a gente precisa que é daqui que a gente sobrevive, mas não quero isso pros meus filhos não. (Caderno de campo, 11/08/2019).

Percebe-se, nos relatos dos agricultores, que a sucessão familiar é um dilema nos polos agroflorestais devido à falta de interesse dos jovens em permanecer na propriedade. A proximidade com o meio urbano permite que alguns jovens conciliem as atividades no lote com estudos fora do assentamento, fica evidente que eles almejam entrar no mercado de trabalho urbano, comprometendo a continuidade dos polos agroflorestais.

$\mathrm{Na}$ agricultura familiar, estes e outros processos têm promovido aquilo que Abramovay et alii (1998) têm chamado de crise de reprodução social. Tal fato decorre, por uma série de motivos, entre eles a alteração dos padrões e as condições e possibilidades econômicas que o mundo rural hoje oferece, não garantindo a permanência da juventude rural junto à propriedade dos pais. Ou seja, o meio rural está envelhecendo, os agricultores têm baixa escolaridade e dificuldades de produzir renda suficiente e regular, fatores estes que têm gerado fortes obstáculos à permanência dos jovens nas propriedades e às possibilidades destes vislumbram o meio rural como um local adequado para o projeto de suas vidas.

Nos três polos analisados, a maioria dos jovens é constituída por estudantes, seguido do trabalho não remunerado, que é o trabalho na lavoura da família ou em atividades domésticas não remuneradas. Cabe informar que grande parte dos jovens concilia essas atividades.

Com exceção do polo Custódio Freire, poucos jovens trabalham por conta própria ou como empregados permanentes. Porém, quando acrescentado à porcentagem daqueles que procuram emprego fora da propriedade rural, traz incerteza em relação à continuidade das atividades desenvolvidas pelo polo.

Destaca-se também o percentual de jovens do polo Custódio Freire que são empregados permanentes. Nesse polo verificou-se maior quantidade de divisão de lotes para construção de moradia para os filhos dos assentados. Pela proximidade com o núcleo urbano, cerca de $20 \mathrm{~km}$ do centro de Rio Branco, os moradores têm fácil acesso ao mercado de trabalho.

É possível verificar que nos polos analisados a maioria dos jovens frequenta o ensino médio. Destaca-se o percentual de jovens do polo Geraldo Fleming que cursa esse nível de ensino, o que pode ser explicado pelo fato de esse polo apresentar, proporcionalmente, a maior quantidade de jovens na faixa etária de treze a dezoito anos.

Outro dado relevante é o elevado percentual de jovens do polo Wilson Pinheiro que frequentam o nível superior. Esta situação reflete a falta de interesse de grande parcela dos jovens em continuar na produção agrícola. Isto pode expressar a busca de melhor qualificação para inserção no mercado de trabalho urbano. 


\section{Considerações Finais}

Este trabalho abordou variáveis no âmbito da produção rural que interferem na segurança alimentar dos agricultores familiares, propiciando uma visão mais ampla do tema e das especificidades de uma realidade territorial rural. A abordagem sobre a organização familiar foi realizada com base na perspectiva de gênero ao privilegiar os relatos das mulheres.

$\mathrm{O}$ autoconsumo é reconhecido pela literatura como um elemento importante para a segurança alimentar dos agricultores familiares. Porém, os produtores dos polos agroflorestais apontaram que existem diversos fatores que impedem o aumento da produção para o autoconsumo, destacando-se o tamanho dos lotes. Além disso, a pouca disponibilidade de mão de obra, os problemas de fertilidade do solo impedem a produção de algumas culturas que formam a base da alimentação. Dessa forma, a renda agrícola permite acesso a alimentos básicos, como feijão e arroz, que não são produzidos nos lotes.

Mesmo não sendo uma produção direcionada exclusivamente para o mercado, estes fatores impedem que todos os produtos necessários à alimentação das famílias sejam oriundos dos lotes.

Um dos entraves verificados nos polos é o fato de que as associações não participam do processo de organização produtiva. Elas atuam como interlocutores entre os produtores e as instâncias do Estado. Os gestores públicos, juntamente com as lideranças locais, devem desenvolver projetos para o fortalecimento dessa área. A oferta de capacitações sobre associativismo e cooperativismo, com foco nos benefícios que essas organizações podem gerar em termos de acesso a programas de compras governamentais e financiamentos, pode contribuir para despertar o interesse dos produtores para essas atividades.

Por meio de diálogos com os produtores é possível perceber que muitos deles compreendem a importância para a saúde em reduzir o uso de agrotóxicos na produção. Mesmo assim eles apontam diversas dificuldades para o desenvolvimento do cultivo orgânico. $\mathrm{O}$ projeto promovido pela Prefeitura para a fabricação de composto orgânico é uma iniciativa de estímulo. Porém, é necessária a realização de projetos que tirem dúvidas dos produtores em relação a essa forma de produção. Projetos na área de comercialização específicos que valorizem a qualidade dos produtos orgânicos podem fortalecer a atividade nos polos.

Analisando os relatos registrados nos cadernos de campo, é possível afirmar que a política pública contribuiu para a melhoria da segurança alimentar de maioria dos assentados, uma vez que, antes de ingressarem nos polos, as dificuldades referentes à alimentação eram significativas. A pesquisa qualitativa revelou que, mesmo diante das dificuldades de infraestrutura, os produtores consideram boa a vida nos polos em comparação à cidade, onde o custo de vida é maior e há recrudescimento da violência. Nesse sentido, pode-se afirmar que a satisfação dos beneficiários indica a efetividade da política pública analisada. Dilemas existem, mas não impedem ser significativo o grau de satisfação de viver nos polos.

Há necessidade de uma reformulação da política pública voltada aos polos agroflorestais e da realização de um planejamento voltado para novas demandas relacionadas à manutenção e mudanças do mercado no sentido de avançar na organização produtiva e social. Igualmente, faz-se necessário pensar em estratégias que fortaleçam o papel dos jovens nas atividades do campo e a perspectiva da ressignificação do relacionamento da juventude com o meio rural. 


\section{Referências bibliográficas}

ABRAMOVAY, R. (Coord.) Juventude e agricultura familiar: desafios dos novos padrões sucessórios. Brasília: Unesco, 1998.

CARDIA, L. M. Cumprindo trajetos, refletindo sobre a memória: colonos e seringueiros migrantes em Rio Branco, Acre - uma abordagem antropológica. Rio Branco: Edufac, 2010.

CARNEIRO, M. J. O Ideal Rurbano: campo e cidade no imaginário de jovens rurais. In: SILVA, F.C.T.; SANTOS, R.; COSTA, L.F.C. (Orgs.). Mundo Rural e Política: ensaios interdisciplinares. Rio de Janeiro: Campus, 1998. p. 94-118.

CASTELO, C. E. F. Experiências de seringueiros de Xapuri no Estado do Acre e outras histórias. 2014. 396 f. Tese (Doutorado no Programa de Pós-Graduação em História Social) Faculdade de Filosofia, Letras e Ciências Humanas, Universidade de São Paulo, São Paulo.

GRISA, C. et alii. Desenvolvimento local, políticas públicas e meios de vida: uma análise do Programa de Aquisição de Alimentos (PAA). In: $47^{\circ}$ Congresso da SOBER, Anais.. Porto Alegre. 2009

LOPES, D.L. Diário de Campo: o registro da reconstrução da natureza e da cultura. In: Sociologia Rural: questões metodológicas emergentes. Presidente Venceslau: Letras à Margem, 2002.

PAULA, R. Lixo vira adubo nas mãos de produtores rurais. Desafios do Desenvolvimento. Ano 11, n. 82 Brasília, IPEA: 2014.

PONTES, C. J. F. A guerra no inferno verde: segundo ciclo da borracha, o front da Amazônia e os soldados da borracha. South American Journal of Basic Education, Technical and Technological, v. 2, p. 56-67, 2015.

RIO BRANCO. Lei $n^{o}$. 1.484 de 2 de dezembro de 2002. Cria os pólos agroflorestais que específica e regulamenta os arts. 111 e seguintes da lei orgânica do município, que trata sobre a política agrícola e fundiária, com os fundamentos dos arts, 186 e 189 da Constituição Federal.

SAFRA. Relatório de gestão do exercício de 2016. Rio Branco, 2017.

SAFRA. Ações da SAFRA no Polo Agroflorestal Geraldo Fleming. Rio Branco, 2018.

SENAR. Sistemas Agroflorestais (SAFs): conceitos e práticas para implantação no bioma amazônico. Brasília: SENAR, 2017.

TONI, F. Gestão florestal na Amazônia brasileira: avanços e obstáculos em um sistema federalista. La Paz: CIFOR/IDRC, 2006. 